

\title{
Levantamento das concepções maternas acerca das habilidades sociocomunicativas de bebês
}

\author{
Assessment of maternal conceptions on the communicative skills of babies
}

\author{
Thiago Francisco de Andrade ${ }^{[a]}$, Frankleudo Luan de Lima Silva ${ }^{[a]}$, Ranielly Cristina Silva Santos ${ }^{[b]}$, \\ Raquel Souza Coelho ${ }^{[\mathrm{s}]}$, Andreza Gomes de Souza ${ }^{[b]}$, lanna Oliveira Barreto ${ }^{[b]}$, Jacqueline Ramos \\ Loureiro Marinho[ ${ }^{[c]}$, Mariana Couto Assis ${ }^{[b]}$, Laisy de Lima Nunes ${ }^{[0]}$, Fabióla de Sousa Braz Aquino ${ }^{[d]}$
}

\footnotetext{
${ }^{[a]}$ Doutorandos do Programa de PósGraduação em Psicologia Social da Universidade Federal da Paraíba (UFPB), João Pessoa, PB - Brasil, e-mails:

thiagoandradepsi@gmail.com; frankleudo.lima-silva@hotmail.com; la.laisy@hotmail.com

${ }^{[b]}$ Graduados em Psicologia pela Universidade Estadual da Paraíba (UEPB), Campina Grande, PB - Brasil, e-mail: raniellycss@hotmail.com; raquelsouzacoelho@gmail.com; andreza_gsouza@hotmail.com; iannabarreto@yahoo.com.br; maricouto.psi@gmail.com

${ }^{[c]}$ Graduada em Psicologia, residente em Saúde Materno-Infantil na Universidade Federal do Rio Grande do Norte (UFRN), Natal, RN - Brasil, e-mail: jacque_loureiro@hotmail.com

${ }^{[\mathrm{d}]}$ Doutora em Psicologia Social, professora do Departamento de Psicologia e do Programa de PósGraduação em Psicologia Social da Universidade Federal da Paraíba (UFPB), João Pessoa, PB - Brasil, e-mail:

fabiolabrazaquino@gmail.com
}

Recebido: 14/09/2012 Received: 09/14/2012

Aprovado: 13/03/2013 Approved: 03/13/2013

\section{Resumo}

As expectativas dos pais em relação às capacidades de seus filhos, bem como seu conhecimento sobre desenvolvimento infantil, influenciam as formas de interação com seus bebês. Seguindo essa linha, o presente estudo investigou as concepções maternas acerca das habilidades sociocomunicativas de bebês no primeiro ano de vida e sua influência no cuidado materno. Foi utilizado o The Pragmatics profile of everyday communication skills in children, uma entrevista estruturada que aborda os aspectos sociopragmáticos da linguagem. Participaram desse estudo 66 mães de bebês de 6, 9 e 12 meses. Os resultados obtidos indicaram variações das concepções maternas em função da idade dos bebês. Observou-se que os bebês passam a apresentar, gradualmente, habilidades comunicativas e gestos mais complexos e sofisticados no sentido de promover ou responder a um comportamento visando à interação social. Verificou-se que os relatos maternos refletiram certo desconhecimento no que se refere à capacidade de comunicação de seus filhos. Identificaram-se diferenças nas concepções maternas em função do nível instrucional e de características individuais infantis como a idade dos bebês pesquisados. Entende-se que esses resultados contribuem para a compreensão das concepções maternas acerca das habilidades sociocognitivas e comunicativas infantis, e que estas possuem repercussões nas interações estabelecidas e nas práticas de cuidado materno. Ademais, os resultados obtidos podem ser úteis para subsidiar programas de intervenção com mães e bebês já no primeiro ano de vida em espaços de saúde e educação infantil.

Palavras-chave: Cognições parentais. Habilidades de comunicação. Bebê.

\section{Abstract}

The parents' expectations about their children capacities, as well as their knowledge about infant development, influence the way they interact with their babies. Following this line of thought, this paper investigated maternal perceptions about the babies' communicative skills in the first year of life and its influence in the maternal care. The Pragmatics Profile of Everyday Communication Skills in Children was used, a structured interview in which the aspects of social-pragmatic dimension of language are analyzed. Sixty-six mothers of 6, 9 and 12 months-old babies participated of the study. The results indicated maternal conceptions variations related to the age of the

Psicol. Argum. 2014 jan./mar., 32(76), 105-115 
babies. We observed that the babies gradually presented more complex communicative skills and more sophisticated gestures to promote or respond to a behavior related to social interaction. We found that maternal reports reflected some misunderstanding with regard to the communication skills of their children. We identified differences in maternal conceptions depending on the maternal instructional level and children's individual characteristics like age of the infants studied. The data collected for this study contribute for the comprehension of maternal conceptions about infant social cognitive and communicative skills, and its consequences to the established interactions and maternal care. Furthermore, the results can be useful to support intervention programs with mothers and babies already at the first year of life.

Keywords: Parental cognitions. Communication skills. Baby.

\section{Introdução}

Os estudos referentes ao desenvolvimento humano têm demonstrado que, além da importância dos fatores biológicos, a influência dos componentes socioculturais é fundamental para a compreensão do desenvolvimento inicial. Nessa linha de raciocínio, destaca-se o papel da interação social como principal fator do desenvolvimento humano, responsável pela gradativa inserção dos sujeitos no universo sociocultural. Esse pressuposto foi defendido por Vygotsky $(1984,2000)$, para quem o desenvolvimento humano se constitui numa gradativa apropriação e internalização de práticas culturais, mediadas e compartilhadas entre sujeitos de uma mesma cultura.

As ideias de Vygotsky relativas ao papel da interação social e dos membros mais competentes da cultura para o desenvolvimento infantil têm sido resgatadas com frequência na literatura acerca do desenvolvimento humano (Braz Aquino \& Salomão, 2010, 2011; Nogueira \& Seidl de Moura, 2007; Piccinini et al., 2001; Seidl de Moura \& Ribas, 2004), especialmente nas pesquisas que exploram o papel das interações iniciais no desenvolvimento infantil. Nesses estudos são exploradas as relações entre as concepções maternas sobre o desenvolvimento infantil e o modo como estas têm impacto nas interações adulto/criança, com destaque na relevância da qualidade da interação durante os primeiros anos de vida para o desenvolvimento posterior da criança, especialmente em relação à comunicação, cognição e socialização.

Pressupondo-se que as interações sociais são fatores que engendram o desenvolvimento infantil (Vygotsky, 2000), investigações relativas às concepções maternas sobre as habilidades sociocomunicativas de bebês mostram-se relevantes pela influência que exercem essas concepções nas práticas de cuidado e nas interações adulto/criança em diversos contextos.

De acordo com Lordelo, Fonseca e Araújo (2000), o adulto, especialmente a figura materna, é o responsável pelo estabelecimento das interações com bebê, sendo estas as matrizes com as quais se constrói o desenvolvimento. Nesse sentido, apesar de se entender que o desenvolvimento humano se desmembra durante e pelas interações da criança com o adulto, atribui-se a este último um peso maior nas fases iniciais do desenvolvimento. Essa assimetria adulto/criança não implica passividade, uma vez que é considerada imprescindível para o estabelecimento de um sistema de comunicação aqui entendido como caracterizado pela reciprocidade nas interações.

Nessa linha teórica estão pesquisas que se detêm na análise das concepções, práticas parentais e suas repercussões para o desenvolvimento infantil (Harkness \& Super, 2006; Kobarg e Vieira, 2008; Reznick \& Schwartz, 2001). Para esses autores, as práticas parentais e as interações da mãe com o bebê são baseadas tanto em expectativas, valores e crenças culturalmente arranjadas, tácitas ao comportamento diário, como na organização do ambiente destinado à criança.

Essas discussões remetem à concepção de nicho desenvolvimental, elaborada por Harkness e Super (2006), que enfatiza a importância do contexto no desenvolvimento humano. Tal conceito, que permite situar as diversas influências extrínsecas ao organismo e seu impacto no desenvolvimento, é aqui retomado por destacar a influência da cultura nas 
crenças e práticas parentais de cuidado infantil. Além disso, a noção de nicho desenvolvimental engloba três dimensões ou sistemas, os quais, articulados, balizam, por assim dizer, as trajetórias desenvolvimentais humanas, a saber: o contexto físico e social da criança; as práticas educacionais e culturalmente determinadas da sociedade em que a criança vive; e a psicologia dos cuidadores, isto é, as características psicológicas, as crenças e práticas parentais daqueles que são responsáveis pelos arranjos de cuidado.

Kobarg e Vieira (2008) acrescentam que fatores como os contextos (cultural, ecológico e social) irão interferir diretamente na formação dessas concepções. Já Seidl de Moura et al. (2004) apontam o ambiente físico e social como fatores que irão transformar essas concepções e as práticas delas decorrentes.

Pesquisadores como Feldman e Reznick (1996) entram nesse debate sugerindo que as expectativas dos pais quanto às capacidades e potencialidades dos filhos e o conhecimento parental sobre desenvolvimento infantil são fatores que fortemente orientam a forma como os pais vão interagir com seus filhos. Para estes mesmos autores, um componente fundamental nas interações sociais seria a concepção parental acerca da habilidade de comunicação intencional dos bebês, expressa por meio de gestos e vocalizações coordenados e manifestos de forma deliberada. Segundo esses pesquisadores, os pais que percebem a intencionalidade do bebê como natural e conhecem os estágios do desenvolvimento infantil terão expectativas equilibradas e estabelecerão com os infantes interações sociais que contribuem para um desenvolvimento saudável, pelo menos do ponto de vista social.

Sobre essa questão, pesquisadores (Lordelo, Fonseca \& Araújo, 2000; Piccinini et al., 2001; Ribas Jr., Seidl de Moura \& Bornstein, 2007) lembram que, se a interação é influenciada pela crença, seria possível compreender de que forma ocorrem os diferentes padrões interativos estabelecidos entre adultos e crianças desde os primeiros meses e anos de vida. Na perspectiva de Kobarg e Vieira (2008), o conhecimento acerca das concepções parentais sobre o desenvolvimento infantil poderia ser usado por profissionais, especialmente das áreas da saúde e da educação, para uma melhor atuação, pois, conforme esses autores, a partir dessas concepções os profissionais poderiam compreender tanto as ideias de mundo e o modo de vida das famílias quanto a forma como essas concepções afetam a saúde dos indivíduos.

Em consonância com Ribas Jr., Moura e Bornstein (2007), para quem as pesquisas sobre relações entre diferentes tipos de cognições parentais ainda são consideradas escassas, a presente pesquisa buscou investigar as concepções maternas acerca das capacidades sociocomunicativas de bebês no primeiro ano de vida, por entender que tais concepções regulam as atitudes e práticas de cuidado parental e, por conseguinte, são fatores que influenciam o desenvolvimento sociocognitivo e linguístico infantil.

\section{Método}

No presente estudo foi realizada uma pesquisa de campo com delineamento transversal, que é amplamente utilizada em pesquisas desenvolvimentais, visto que tem por característica o estudo de grupos de diferentes faixas etárias ao mesmo tempo (Cole $\&$ Cole, 2004). A pesquisa somente foi desenvolvida após a devida apreciação e aprovação do Comitê de Ética em Pesquisa da Universidade Estadual da Paraíba, com o protocolo 0337.0.133.000-09.

\section{Participantes}

Um total de 66 mães de bebês aos 6, 9 e 12 meses responderam às entrevistas. A idade das mães variou entre 18 e 39 anos, média de 28,58 ( $\mathrm{DP}=5,75$ ). Desse total, 22 mães, com idade média de 27,41 (DP = 5,17), tinham bebês aos 6 meses; 19 mães, com idade média de 29,95 ( $\mathrm{DP}=5,42$ ), tinham bebês aos 9 meses; e 25 mães de bebês aos 12 meses tinham média de idade de 28,56 (DP=6,43).

Quanto aos critérios de inclusão da pesquisa, foi estabelecido que as participantes fossem mães casadas, com idade igual ou superior a 18 anos, residentes em seus próprios domicílios e de status ocupacional e instrucional diversos. Essas mães foram contactadas em postos de saúde ou por indicação. No tocante ao gênero dos bebês, 28 eram do sexo masculino e 38 do sexo feminino (bebês aos 6 meses: 12 masculinos e 10 femininos; aos 9 meses: 8 masculinos e 11 femininos; e aos 12 meses: 8 masculinos e 17 femininos).

Psicol. Argum. 2013 jul./set., 32(76), 105-1 15 
Instrumento

Para investigar as concepções acerca das habilidades sociocomunicativas dos bebês foi utilizado o The pragmatics profile of everyday communication skills in children (Dewart \& Summers, 1995), uma entrevista do tipo estruturada que passou por um processo de adaptação semântica realizado por Braz Aquino, Salomão, Araújo, Queiroga, Gabarra e Lopes (2007). Essa entrevista concentra-se em aspectos voltados à análise da dimensão sociopragmática da linguagem.

0 The pragmatic profile of everyday communication skills in children aborda quatro aspectos do desenvolvimento da pragmática: o desenvolvimento da função comunicativa (a maneira como a criança torna-se apta a expressar suas intenções e a dar informações por meio de uma variedade de comportamentos comunicativos); as respostas à comunicação (a maneira como a criança reage e compreende a comunicação de outras pessoas); a participação em interações sociais e na conversação (a criança percebida como participante na interação) e as variações no contexto (tais como o tempo, o local e as pessoas envolvidas na interação). Esta última sessão não foi objeto de análise neste estudo, dado que se trata de aspectos mais gerais do cotidiano infantil. Adotouse uma abordagem qualitativo-descritiva das informações e relatos sobre como a criança se comunica em sua vida diária. Essas informações podem ser obtidas de pais, professores, profissionais da área de saúde e da educação, constituindo-se num importante meio para detecção e intervenção precoce na área da comunicação e da linguagem.

\section{Procedimentos para coleta de dados}

A participação de todas as mães levou em consideração os aspectos éticos pertinentes à investigação envolvendo seres humanos, conforme a resolução no 196/96 do Conselho Nacional de Saúde. A participação delas foi voluntária e esteve condicionada à assinatura do Termo de Consentimento Livre e Esclarecido. As entrevistas foram realizadas em local reservado de unidades básicas de saúde, evitando-se possíveis interferências. A única instrução dada à mãe foi para que respondesse às questões pensando em seu bebê na idade em que ele se encontrava no momento da entrevista. Foi ainda ressaltado que não há na entrevista respostas certas ou erradas, já que o mais importante era obter a opinião delas sobre aspectos relacionados ao desenvolvimento dos bebês.

\section{Procedimentos para análise dos dados}

Foi realizado um levantamento de frequência das respostas das mães às questões da entrevista que demonstraram as variações em cada seção do The pragmatics profile of everyday communication skills in children. As categorias utilizadas para a análise de dados partiram do próprio instrumento de coleta de dados. A primeira fase da análise constou do levantamento das frequências de respostas mais prevalentes referidas pelas mães em cada grupo de idade estudada. Num segundo momento, as falas maternas foram organizadas considerando cada idade e período do desenvolvimento dos bebês nos três grupos de idades estudadas. Os relatos maternos foram discutidos com base em pesquisas no campo da linguagem, sob o prisma sociocomunicativo, destacando a ideia de que as habilidades sociocomunicativas infantis nos primeiros anos de vida podem influenciar as concepções maternas e as interações da mãe com o bebê.

\section{Resultados e discussão}

Do conjunto de resultados obtidos nesse estudo, considerou-se pertinente explorar os aspectos relativos ao nível instrucional materno, idade materna e idade dos bebês, uma vez que pesquisas nessa área (Braz Aquino e Salomão, 2011; Kobarg \& Vieira, 2008; Ribas Jr., Moura \& Bornstein, 2007; Seidl de Moura et al., 2004; Silva, 2003) discutem o impacto desses aspectos nas concepções dos adultos acerca do desenvolvimento infantil, em especial, nas interações da mãe com a criança.

Em relação ao nível instrucional materno, verificou-se que aproximadamente $34 \%$ das mães tinham o ensino fundamental completo ou incompleto; $46 \%$ tinham o ensino médio completo ou incompleto e $20 \%$ tinham o ensino superior completo ou incompleto. Notou-se que as mães com maior nível de escolaridade deram respostas mais elaboradas e com mais informações acerca das habilidades sociocomunicativas do seu bebê. Por outro lado, as 
mães com menor nível de escolaridade pareciam estar hesitantes e inseguras ao responder à entrevista, e apresentaram dificuldades para compreender determinadas questões. Algumas das mães desse grupo pediram, inclusive, explicações acerca de alguns itens do instrumento.

Esses resultados também foram observados por Silva (2003) que verificou em seu estudo que os níveis instrucional e ocupacional maternos foram elementos significativos e influenciadores do conhecimento das mães sobre aspectos da vida de seus filhos. Pesquisadores como Ribas Jr., Moura e Bornstein (2007) defendem que uma melhor compreensão das cognições parentais sobre o desenvolvimento infantil favorece um melhor entendimento sobre esse desenvolvimento e as interações que se estabelecem entre pais e filhos, interferindo, inclusive, nas práticas de criação.

Acrescenta-se a isso o fato de que essas mães e seus bebês foram atendidos em unidades básicas de saúde, o que pode provê-las de informações importantes sobre o desenvolvimento de seus bebês, diferente das mães que criam os filhos a partir do que lhes é transmitido pelos agentes mais próximos à criança (avós, tios, babás), que, em geral, estruturam os cuidados dirigidos a ela conforme padrões, crenças e práticas de seu nicho de desenvolvimento (Harkness \& Super, 2006).

No que concerne à idade materna, verificou-se que as concepções das mães com mais idade não divergiram consideravelmente das concepções das mães mais jovens, mesmo no caso das mães primíparas. Assim como nos achados de Silva (2003), nesta pesquisa verificou-se que a diferença de idade das mães não foi necessariamente um elemento que influenciou sua concepção em relação às habilidades sociocomunicativas dos filhos.

Quanto à idade dos bebês, observou-se que quanto mais idade, mais se ampliavam os conhecimentos maternos sobre o comportamento deles. De forma geral, as mães de bebês aos 12 meses apresentavam mais elementos para ilustrar sua resposta. Por outro lado, as mães de bebês com menos idade (no caso de bebês aos 6 meses) apresentaram descrições mais breves em relação às habilidades comunicativas deles. Esses dados encontram apoio em estudo desenvolvido por Seidl de Moura et al. (2004), no qual os autores aludem ao fato de que, com o aumento da idade do bebê, a mãe parece ter mais conhecimento sobre o desenvolvimento dele.
No que se refere ao levantamento das concepções maternas acerca das habilidades sociocomunicativas dos bebês, pôde-se identificar por meio das entrevistas variações nas concepções das mães em relação às habilidades comunicativas dos bebês nos três períodos do primeiro ano de vida. Esses resultados são apresentados e discutidos a seguir.

\section{a) Funções Comunicativas}

Quanto à questão relativa à concepção materna acerca das habilidades dos bebês para conseguir atenção materna, as mães de bebês de 6 meses responderam que eles "choram" (82\%). Também foram mencionados por essas mães comportamentos como "puxando você" (18\%); "vocalizando" (9\%) e "chamando mamãe" (5\%). Aos 9 meses, as mães relataram que $37 \%$ de seus bebês "choram", "puxam a mãe" (32\%). Comportamentos como "chamando mamãe" (26\%) e "vocalizando" (11\%) também foram relatados. Entre as mães de bebês de 12 meses foram referidos comportamentos como "chamando mamãe" (48\%); "choram" (44\%); "puxando você" $(16 \%)$.

Num estudo anterior que investigou as concepções maternas sobre as habilidades comunicativas de bebês no primeiro ano de vida, Braz Aquino, Ribeiro, Barbosa e Braga (2009) descobriram que o choro foi, segundo as mães, o principal recurso comunicativo utilizado pelos bebês marcadamente aos 6 meses, o que se altera aos 9 e 12 meses, quando as mães relataram outros tipos de comportamento utilizado pelos bebês, tais como vocalizar, puxar a mãe e chamar mamãe.

No presente estudo, as mães dos bebês de $9 \mathrm{me}$ ses relataram que, para chamar a atenção materna, seus filhos tinham comportamentos como chorar, puxar a mãe e chamar mamãe. Também para Brazelton (1994), por volta dos 9 meses, o choro deixa de ser o único meio utilizado pelo bebê para chamar a atenção materna, pois ele passa a explorar os sons da fala, produzindo novos sons ou sílabas, além de fazer uso de gestos. Já o estudo de Braz Aquino e Salomão (2007), obteve que entre as idades de 9 e 12 meses os bebês tentavam chamar a atenção do adulto através do choro, puxando a mãe, apontando e dando os braços, o que sugere que nesse período os bebês já utilizam gestos como apontar, mostrar e dar.

Psicol. Argum. 2013 jul./set., 32(76), 105-115 
Em relação à concepção materna acerca das habilidades comunicativas dos bebês para demonstrar ao adulto algo que conhece, as mães de bebês de 6 meses relataram mais frequentemente que seus bebês "sorriem", "observam e olham atentos" (27\%), "fazem um gesto", "tentam pegá-lo" (18\%); "vocalizam" (14\%), e "não demonstram nenhuma reação" (9\%). Entre as mães de bebês de 9 meses, foram relatadas habilidades como "tenta pegar" (26\%), "faz um gesto" (21\%), "vocaliza" (16\%) e "sorri"; "faz um som relacionado" como, por exemplo, "au-au" para cachorro, e "grita" (11\%). No grupo de mães de bebês de 12 meses, foram mencionados "faz um som relacionado", (32\%), "faz um gesto" (28\%) e "vocaliza" (12\%). Nota-se que o uso de gestos e o ato de sorrir foram relatados pelas mães nas três idades pesquisadas. Esses dois comportamentos têm sido apontados como fundamentais para o início e o estabelecimento da comunicação nos primeiros meses de vida do bebê (Papaeliou \& Trevarthen, 2006; Striano \& Rochat, 1999). Já aos 9 e 12 meses estes gestos passam a ser utilizados de forma coordenada com outros recursos comunicativos mais sofisticados, tais como a vocalização de sons relacionados aos objetos (Tomasello, 1998; Tomasello, Carpenter, Call, Behne, \& Moll, 2005). Estes resultados são corroborados pelos dados encontrados por Braz Aquino e Salomão (2011).

Ainda foram relatadas, por mães de bebês de 9 e 12 meses, habilidades como fazer um som relacionado para comunicar ao adulto algo que conhece. Essa habilidade não foi mencionada pelas mães de bebês de 6 meses. Tal comportamento tem respaldo na literatura, uma vez que autores como Brazelton (1994) afirmam que a partir dos 9 meses os bebês passam a explorar os sons da fala, de modo a produzir novos sons ou sílabas, embora ainda não estejam relacionados a significados específicos. Já o comportamento de "observar e olhar atento", predominantemente referido pelas mães de bebês de 6 meses, confirma o que autores como Striano e Rochat (1999) e Tomasello (2003) defendem quando mencionam que os bebês, por meio de olhares e gestos, interagem diadicamente tanto com objetos quanto com pessoas.

Também foi aludido pelas mães, das três idades estudadas, o comportamento de "vocalizar". Esse dado foi verificado no relato das mães de bebês de 6 meses (12\%) ao mencionarem que seus bebês vocalizam quando querem comunicar algo ao adulto. Esses resultados ganham apoio no estudo de Nogueira e Seidl de Moura (2007), que observaram que já a partir dos 2 meses, os bebês são capazes de vocalizar espontaneamente imitando alguns sons que ouvem à sua volta. Verificou-se que entre as mães de bebês de 9 meses há predominância nessa resposta, o que confirma a afirmativa de Tomasello (2003) referente à aquisição da capacidade de comunicação intencional no final do primeiro ano de vida. Também foi mencionado pelas mães de bebês de 6 meses, o comportamento de "sorrir", como forma utilizada pelos bebês para comunicar algo que conhece. Conforme Trevarthen (1979) e Seidl de Moura e Ribas (2004), esse comportamento faz parte do repertório inicial do bebê; para esses autores, comportamentos como o sorriso, o choro ou outras expressões faciais são eficazes para deflagrar as interações iniciais e consistem num importante sinal social. A menção a esse comportamento decresceu nos relatos das mães de bebês de 9 e de 12 meses, uma vez que nesses períodos os bebês utilizam outras formas de interação como, por exemplo, apontar, vocalizar sílabas ou palavras, entre outras. O comportamento "faz um gesto" e "tenta pegar" foi mencionado por $18 \%$ das mães de bebês de 6 meses, este último característico nos bebês a partir dos 9 meses. 0 percentual aumentou gradativamente entre as mães de bebês de 9 meses (21\% e 26\%, respectivamente). Aos 12 meses, 28\% das mães citaram esses comportamentos.

\section{b) Resposta à comunicação}

Em relação às concepções maternas no que diz respeito aos comportamentos das mães para chamar a atenção do bebê, as mães de bebês do grupo de 6 meses relataram que "dizem o nome dele" (86\%), "tocam nele" (23\%), "brincam ou cantam para ele" (14\%) e "falam 'mamãe' ou outra coisa" (9\%) como formas de atrair sua atenção. Já as mães dos bebês de 9 meses mencionaram "dizer o nome dele" (63\%), e "tocar nele" (11\%). De acordo com as respostas dadas pelas mães de bebês com 12 meses, as principais formas utilizadas por elas para conseguir a atenção de seu filho são "dizendo o nome dele" (76\%) e "gritando o nome dele" (8\%).

Como pode ser observado, a estratégia mais utilizada pelas mães para obter a atenção do seu bebê durante o sexto, o nono e o décimo segundo meses foi 
"chamar o bebê pelo nome" e "tocar no bebê". Autores como Trevarthen (1979) afirmam que pais e filhos concentram atenção um no outro através de "protoconversas", que são interações sociais que incluem, além da vocalização, o olhar face a face e o toque, que expressam e compartilham emoções básicas. Já Tomasello (2003) assinala que os bebês a partir de 6 meses interagem diadicamente com outras pessoas e objetos, expressando emoções e respondendo a elas em uma sequência alternada. Braz Aquino e Salomão (2011), por sua vez, afirmam que o comportamento de "chamar o bebê pelo nome" pode indicar que as mães percebem que os bebês reconhecem seu próprio nome entre as demais palavras de seus contextos. Nota-se que a partir dos 9 meses, ocorreu uma menor frequência de respostas do comportamento "tocar o bebê", que pode estar relacionada à maior mobilidade física adquirida pelo bebê. Como afirma Brazelton (1994), “(...) um bebê de 9 meses raramente fica no colo da mãe ou do pai” (p. 145); ao contrário, ele está agora em constante exploração do ambiente tornando os contatos físicos com seus cuidadores não tão frequentes.

Com relação às respostas fornecidas pelo bebê diante de solicitações maternas em momentos de interação, as mães de bebês de 6 meses relataram que eles respondem à fala e aos comportamentos maternos, principalmente, olhando interessado e fazendo contato com os olhos (55\%). Também foi mencionado pelas mães de bebês de 6 meses que estes respondiam as tentativas maternas de interação "sorrindo" (18\%), "juntando-se à conversa usando sons e palavras" (18\%) e "movimentando seu corpo e face" (9\%).

Aos 9 meses, as mães também citaram que seus bebês respondem às mesmas situações "olhando interessados e fazendo contatos visuais" (42\%), "juntando-se à conversa usando sons ou palavras" (21\%), e "movimentando seu corpo e face" (21\%). Entretanto, estas frequências sofreram variações se comparadas às frequências das respostas dadas pelo grupo de mães de bebês de 6 meses, indicando que as mães de bebês de 9 meses percebem melhor os tipos mais complexos de participação interativa.

0 grupo de mães de bebês com 12 meses, por sua vez, relatou que eles "usavam sons ou palavras" (44\%), "faziam contato visual" (28\%), "faziam movimentos de corpo e face" (16\%), e "sorriam" (12\%), como resposta à conduta solicitante da mãe. A frequência das respostas maternas referentes ao comportamento "olhar interessado e fazer contato com os olhos" diminuiu, embora não tenha desaparecido nos relatos de mães de bebês aos 12 meses. Por sua vez, observa-se um aumento na frequência dos relatos das mães que afirmam que seus bebês "juntam-se à conversa usando sons/palavras". É importante que se leve em consideração, nos resultados encontrados, a concepção de "conversa" que as mães pesquisadas possuem. E, dessa forma, a concepção materna acerca dos comportamentos dos bebês e a atribuição de significados dada por elas podem ter influenciado seu relato. Ademais, devido ao fato de a alternativa sugerida pelo instrumento abarcar tanto a articulação de palavras quanto a emissão de outros sons, essas respostas podem ser explicadas pela ocorrência dessa resposta entre mães de bebês de 6 meses. Em suma, os relatos sugerem que as mães percebem uma gradativa aquisição dos signos linguísticos por parte do bebê, sobretudo a partir dos 9 meses, como foi verificado em estudos na área (Braz Aquino \& Salomão, 2011; Brazelton, 1994; Feldman \& Reznick, 1996; Vygotsky, 1996, 1998).

Do conjunto das questões abordadas durante a entrevista foram obtidos resultados sobre as concepções maternas a respeito da compreensão do bebê frente à fala da mãe direcionada a ele, ou seja, como o bebê compreende as intenções comunicativas maternas. Em relação a essa questão, 41\% das mães de bebês de 6 meses mencionaram que o bebê "sorri e olha para ela", "olha para sua face" (55\%), "olha e faz sons" (9\%) e "presta atenção" (5\%), demonstrando com isso compreender que a mãe está se dirigindo a ele. Entre as mães de bebês da faixa etária de 9 meses, os relatos incluíram "sorrir e olhar para a mãe" (47\%), "olhar e fazer sons" (32\%), "olhar para a face da mãe" (16\%) e "prestar atenção" (5\%). Já entre as mães de crianças de 12 meses, os relatos maternos englobaram os comportamentos de "sorrir e olhar para a mãe" (52\%), "olhar e fazer sons" (16\%), "olhar para a face da mãe" (8\%), "responder para a mãe falando" (8\%), "prestar atenção" (4\%), ou eles demonstram "não compreender" (4\%).

0 comportamento de "sorrir e olhar para a face da mãe" pode ser considerado um sinal de compreensão da fala materna por parte dos bebês, relatado nos três períodos evolutivos. Esse resultado encontra sustentação em autores como Trevarthen e Aitken (2001), os quais defendem que em poucas horas após o nascimento o bebê já sorri, e esse sorriso, juntamente com outros comportamentos, é

Psicol. Argum. 2013 jul./set., 32(76), 105-115 
automaticamente percebido como emocional. Para ele, o sorriso do bebê é, desde o segundo mês, um importante sinal social. Já o comportamento de olhar para a face da mãe se constitui num gesto social desde a sexta semana de vida dos bebês; esse tipo de comportamento representa para a mãe o começo da comunicação “consistente” (Trevarthen, 1979).

Já o comportamento de "olhar para a face da mãe", o segundo mais citado entre as mães de crianças de 6 meses, foi menos citado entre as mães de bebês de 9 e 12 meses. Isso provavelmente se deve ao fato de os bebês começarem a utilizar outros recursos comunicativos além do gesto de olhar para a mãe - a resposta "olhar e fazer sons" que aos 6 meses foi citada por $9 \%$ das mães, aos 9 meses foi mencionada por 32\% das mães. Segundo Brazelton (1994), é a partir dos 9 meses que os bebês passam a explorar novos sons e sílabas, até mesmo com a intenção de chamar a atenção dos pais. Já aos 12 meses, o índice de mães que afirmaram que seus filhos olhavam para ela e emitiam sons volta a cair; isso ocorre provavelmente porque durante o décimo segundo mês, conforme 8\% das mães, suas crianças já "respondem à mãe falando". Para Brazelton (1994), ao completar 1 ano de idade, as crianças têm maior domínio sobre a linguagem verbal que, nessa fase, carrega uma intenção comunicativa.

Quanto às concepções maternas sobre as habilidades do bebê em demonstrar a compreensão de uma ordem ou solicitação da mãe, foram observadas variações de respostas, considerando as três faixas de idade. As mães de bebês de 6 meses relataram que eles "não mostravam reação" (50\%), "olhavam, mas pareciam não saber o que fazer" (36\%) e "choravam" (9\%). Já nos relatos das mães de bebês com 9 meses, foram mencionados "olhava para a mãe, mas demonstrando não saber o que fazer" (26\%), "respondia a seu pedido" (26\%), e "não mostrava reação" (11\%). No grupo de mães de bebês de 12 meses foram referidos "respondem a seu pedido" (40\%), "olham para a mãe, mas parecem não saber o que fazer" (24\%), "não mostram reação" (12\%) e "fazem isso como parte de uma rotina" (8\%).

Os relatos maternos ganham apoio nos dados da literatura no que se refere à habilidade dos bebês para compreender um comando materno, dado que tal habilidade dá-se de forma gradual nos bebês, evidenciando-se, principalmente, no final do primeiro ano de vida (Sarriá, 1991; Striano \& Reid, 2006; Tomasello, 2003). Em contrapartida, as respostas "não mostravam reação" (50\%) e "olhavam para a mãe, mas pareciam não saber o que fazer" (36\%), relatadas com maior frequência pelas mães de bebês de 6 meses, podem sugerir uma incompreensão materna acerca dos sinais comunicativos sutis dados pelos bebês durante as interações, tais como olhar para a mãe no momento em que ela se dirige a ele. No entanto, as pesquisas na área relatam que a habilidade de interpretar a intenção comunicativa materna apenas se evidencia entre os 9 e 12 meses de vida (Striano \& Rochat, 1999; Tomasello, 2003). No estudo realizado por Braz Aquino e Salomão (2007) também foi encontrado que a metade das mães de bebês de 9 meses participantes considerava que seus filhos mostravam pouco interesse nessas interações, enquanto que as mães de crianças de 12 meses, já relatavam uma maior responsividade por parte dos bebês. Conforme as autoras, isso pode indicar a aquisição de formas mais complexas de participação destes bebês na interação.

\section{c) Interação e diálogo}

Referente às concepções maternas acerca do comportamento do bebê em interação com a mãe, observa-se que $77 \%$ das mães de bebês de 6 meses responderam que o bebê "sorri e dá gargalhadas", 23\% relataram que ele "olha interessado", e 9\% percebem que "vocalizam ou balbuciam". Entre as mães de bebês de 9 meses, as respostas mais recorrentes foram "sorri e dá gargalhada" (58\%) e "aponta e faz gestos" (16\%). Já as mães de bebês de 12 meses responderam "sorri e dá gargalhada" (40\%), "aponta e faz gestos" (40\%), "usa palavras e frases simples" (16\%) e 8\% disseram que o bebê "conversa".

Os relatos maternos têm respaldo em dados da literatura no que diz respeito às formas utilizadas pelos bebês para participarem ativamente das interações. Os dados sugerem que a interação envolve mais recursos comunicativos com os bebês de 12 meses, quando comparados com as respostas das mães dos bebês de 6 e 9 meses, na medida em que compreende a coordenação entre gesto, olhar e vocalização a um parceiro. Resultados semelhantes foram encontrados em um estudo longitudinal realizado por Florentino (2009), que apresentou o sorriso como principal comportamento do bebê em interações com a mãe. Em outra pesquisa, Braz Aquino e Salomão (2007) constataram que as mães de bebês com 12 meses de idade responderam que seus bebês 
faziam o gesto de apontar. Anteriormente, Volterra, Caselli, Capirci e Pizzuto (2004) mencionaram que o gesto de apontar é um preditor da capacidade linguística subsequente e um gesto eminentemente sociocomunicativo e intencional.

De acordo com as respostas das mães à entrevista, com a idade, as estratégias comunicativas dos bebês para iniciar uma interação tornam-se mais sofisticadas, incluindo gestos comunicativos intencionais como o de dar ou mostrar algo, aproximar-se e olhar para a mãe e puxar a mãe (Sarriá, 1991). Com base na perspectiva sócio-histórica, considera-se imprescindível pontuar que o conjunto de aquisições sociocognitivas e comunicativas do bebê no primeiro ano de vida está fortemente atrelado aos tipos de interações sociais e aos contextos específicos de trocas que se dão entre ele e os sujeitos com os quais interage.

\section{Considerações finais}

Este estudo se propôs a investigar as concepções maternas referentes às habilidades comunicativas de bebês no primeiro ano de vida. O levantamento realizado sugere que a maioria das mães percebeu em seus filhos habilidades comunicativas que variaram em suas configurações nos três períodos do desenvolvimento estudados. Os relatos maternos indicaram a aquisição de habilidades comunicativas mais complexas caracterizadas pela coordenação de gestos com vocalizações, principalmente aos 12 meses.

Numa leitura bidirecional, considerou-se o impacto de variáveis como, nível instrucional e ocupacional materno, idade e o número de filhos das mães pesquisadas, e a idade dos bebês, já que estas medeiam as interações iniciais entre o adulto e a criança (Seidl de Moura et al., 2004). Por sua vez, tais interações são fortemente amparadas por fatores históricos, culturais e sociais que interferem na formação das concepções e práticas maternas de cuidado (Harkness \& Super, 2006; Kobarg \& Vieira, 2008)

Pontua-se a relevância da utilização de instrumentos que busquem apreender as concepções parentais acerca de aspectos do desenvolvimento infantil, tais como as habilidades de comunicação desde os primeiros anos de vida. Essa ideia ganha apoio no argumento de Dewart e Summers (1995), os quais verificaram que as mães que participavam de entrevistas relativas à questão da habilidade de comunicação infantil pareciam se tornar mais conscientes de tal habilidade em seus bebês, devido à experiência de ponderar sobre a existência ou não de tais capacidades em seus filhos. Assim, este estudo reforça a importância da influência das concepções maternas para a promoção de condições estimuladoras do desenvolvimento infantil, bem como das práticas de cuidado materno, traduzidas na estruturação, organização e enriquecimento do ambiente de desenvolvimento dos filhos.

Compreende-se que os dados obtidos a partir do presente estudo podem contribuir para o planejamento de intervenções no cotidiano das mães de bebês no primeiro ano de vida, com ênfase no papel da comunicação e das interações iniciais entre o adulto e o bebê para o desenvolvimento global, tal como mencionado por Braz Aquino, Ribeiro, Barbosa e Braga (2009). Dessa forma, defende-se como oportuna a condução de novos estudos que investiguem esses aspectos nos demais contextos nos quais interagem bebês, crianças e adultos, tais como creches e pré-escolas, pela importância das interações estabelecidas entre os educadores e as crianças, como também pelas contribuições de psicólogos nesses contextos, mediando tais interações e intervindo precocemente em possíveis transtornos associados a prejuízos na comunicação e na linguagem, como o autismo por exemplo.

Ademais, convém pontuar a relevância de estudos que disponibilizem dados empíricos adicionais a respeito de tais concepções em diversos contextos da população brasileira, entendendo que esses estudos podem contribuir para a compreensão acerca das habilidades sociocomunicativas e cognitivas infantis por parte dos cuidadores, o que contribui, portanto, para as interações iniciais entre o adulto e o bebê.

\section{Referências}

Braz Aquino, F. S., Salomão, N. M. R., Araújo, A. P., Queiroga, A. A. T., Gabarra, A. T. P., Lopes, M. C. M. B. C. et al. (2007). Adaptação do Pragmatic Profile para investigar as concepções maternas acerca das habilidades sociocomunicativas de bebês. [Resumo]. In Associação Brasileira de Psicologia do Desenvolvimento (Org.). VI Congresso Brasileiro de Psicologia do Desenvolvimento: contextos de desenvolvimento, educação e cultura. Resumos. (p. 236). Vitória: Espírito Santo.

Psicol. Argum. 2013 jul./set., 32(76), 105-115 
Braz Aquino, F. S., \& Salomão, N. M. R. (2010). Intencionalidade comunicativa: teorias e implicações para a cognição social infantil. Estudos de Psicologia, 27(3), 413-420.

Braz Aquino, F. S., \& Salomão, N. M. R. (2011). Percepções Maternas Acerca das Habilidades Sociocomunicativas de bebês. Psicologia ciência e profissão, 31(2), 252-267.

Braz Aquino, F. S., \& Salomão, N. M. R. (2007). Análise das concepções maternas acerca das habilidades sociocomunicativas de bebês de 9 e 12 meses. [Resumo]. In Associação Brasileira de Psicologia do Desenvolvimento (Org.). VI Congresso Brasileiro de Psicologia do Desenvolvimento: contextos de desenvolvimento, educação e cultura. Resumos. (p. 90). Vitória: Espírito Santo.

Braz Aquino, F. S., Ribeiro, M. Q. S., Barbosa, D. G., \& Braga, M. L. S. (2009). Concepções maternas acerca das habilidades sociocomunicativas de bebês. [Resumo]. In Associação Brasileira de Psicologia do Desenvolvimento (Org.). VII Congresso Brasileiro de Psicologia do Desenvolvimento: desenvolvimento e direitos humanos. Resumos. (pp. 269-270). Rio de Janeiro.

Brazelton, T. B. (1994). Momentos decisivos do desenvolvimento infantil. São Paulo: Martins Fontes.

Cole, M., \& Cole, S. (2004). O desenvolvimento da criança e do adolescente (4 ed.). Porto Alegre: Artmed.

Dewart, H., \& Summers, S. (1995). The Pragmatics Profile of Everyday Communication Skills in children. Windsor: Nfer-Nelson.

Feldman, R., \& Reznick, J. S. (1996). Maternal Perception of Infant Intentionality at 4 and 8 Months. Infant Behavior and Development, 19, 483-496.

Florentino, F. B. (2009). Percepções maternas acerca das habilidades sociocomunicativas de bebês no primeiro ano de vida: um estudo longitudinal. Trabalho de Conclusão de Curso em Psicologia, Universidade Estadual da Paraíba, Campina Grande, Paraíba.
Harkness, S., \& Super, C. M. (2006). Themes and variations: Parental Ethnotheories in Western Cultures. In Rubin K. H., \& Chung O. B. (Org.). Parental beliefs, behavior, and parent-child relations: a cross-cultural perspective. (pp. 61-80). New York: Routledge USA.

Kobarg, A. P. R., \& Vieira, M. L. (2008). Crenças e Práticas de Mães sobre o Desenvolvimento Infantil nos Contextos Rural e Urbano. Psicologia: Reflexão $e$ Crítica, 21(3), 401-408.

Lordelo, E. R., Fonseca, A. L., \& Araújo, M. L. V. B. (2000). Responsividade no ambiente de desenvolvimento: crenças e práticas como sistema cultural de criação de filhos. Psicologia: Reflexão e Crítica, 13(1), 73-80.

Nogueira, S. E., \& Seidl de Moura, M. L. (2007). Intersubjetividade: Perspectivas teóricas e implicações para o desenvolvimento infantil inicial. Revista Brasileira Crescimento e Desenvolvimento Humano, 17(2), 128- 138.

Papaeliou, C. F., \& Trevarthen, C. (2006). Prelinguistic pitch patterns expressing 'communication' and 'apprehension'. Journal of Child Language, 33, 163-178.

Piccinini, C.A., Seidl de Moura, M. L., Ribas, A. F. P., Bosa, C. A., Oliveira, E.A., Pinto, E. B. et al. (2001). Diferentes Perspectivas na Análise de Interação Pais-Bebê/ Criança. Psicologia: Reflexão e Crítica, 14(3), 469-485.

Reznick, J. S. \& Schwartz, B. B. (2001) When is an assessment an intervention? Parent Perception of Infant Intentionality and Language. Journal of the American Academy of Child and Adolescent Psychiatry, 40(1), 11-17.

Ribas Jr., R. C., Seidl-de-Moura, M. L., \& Bornstein, M. H. (2007). Cognições maternas acerca da maternidade e do desenvolvimento humano: uma contribuição ao estudo da psicologia parental. Revista Brasileira de Crescimento e Desenvolvimento Humano, 17(1), 104-113.

Sarriá, E. (1991). Observación de la comunicación intencional preverbal: un sistema de codificación basado en el concepto de categoría natural. Psicothema, 3(2), 359-380. 
Seidl de Moura, M. L., Ribas Jr, R,. C., Piccinini, C. A., Bastos, A. C. S., Magalhães, C. M. C., Vieira, M. L. et al. (2004). Conhecimento sobre desenvolvimento infantil em mães primíparas de diferentes centros urbanos do Brasil. Estudos de Psicologia, 9(3), 421-429.

Seidl de Moura, M. L., \& Ribas, A. F. P. (2004). Evidências sobre características de bebês recém-nascidos: um convite a reflexões teóricas. In Seidl de Moura, M. L. (Org.). O bebê do século XXI e a Psicologia em desenvolvimento. São Paulo: Casa do Psicólogo.

Silva, A. K. (2003). Concepções de mães primíparas sobre o desenvolvimento infantil ao longo do primeiro ano de vida da criança. Dissertação de mestrado, Universidade Federal de Santa Catarina, Florianópolis, Santa Catarina.

Striano, T., \& Rochat, P. (1999). Developmental link between dyadic and triadic social competence in infancy. British Journal of Developmental Psychology, 17, 551-562.

Striano, T., \& Reid, V. M. (2006). Social cognition in the first year. Trends and cognitive science, 10(10), 471-476.

Tomasello, M. (1998). Reference: Intending that others jointly attend. Pragmatics \& Cognition, 6(1/2), 229-243.

Tomasello, M. (2003). Origens Culturais da Aquisição do Conhecimento Humano.( C. Berliner, Trad.). São Paulo: Martins Fontes.
Tomasello, M., Carpenter, M., Call, J., Behne, T., \& Moll, H. (2005). Understanding and sharing intentions: the origins of cultural cognition. Behavioral and Brain Sciences, 28(5), 1-42.

Trevarthen, C. (1979). Communication and cooperation in early infancy: a description of primary intersubjectivity. In Bullowa, M. (Org.). Before speech, the beginning of interpersonal communication. Cambridge: University Press.

Trevarthen, C., \& Aitken, K. J. (2001). Infant intersubjectivity: research, theory and clinical applications. Journal of child psychology and psychiatry, 42(1), 3-48.

Vygotsky, L. S. (1996). El primer año. In: Vigotski, L. S. Obras Escogidas: Psicología infantil. (pp. 275318). Tomo IV. (Kuper L., Trad.). Madrid: Visor. (Originalmente publicado em 1932).

Vygotsky, L. S. (1998). O desenvolvimento psicológico na infância. (C. Berliner, Trad.). São Paulo: Martins Fontes.

Vygotsky, L. S. (2000). A Formação Social da Mente. São Paulo: Martins Fontes. (Originalmente publicado em 1984).

Volterra, V., Caselli, M. C., Capirci, O., \& Pizzuto, E. (2004). Gesture and the emergence and development of language. In Tomasello, M., \& Slobin, D. (Org.). Elizabeth Bates: A Festschrift. Mahwah, NJ: Lawrence Erlbaum Associates.

Psicol. Argum. 2013 jul./set., 32(76), 105-115 